\title{
Potential role of age, sex, body mass index and pain to identify patients with knee osteoarthritis
}

\author{
Duarte PEREIRA, ${ }^{1,2}$ Milton SEVERO, ${ }^{1,2}$ Elisabete RAMOS, ${ }^{1,2}$ Jaime BRANCO, ${ }^{3,4}$ \\ Rui A. SANTOS, ${ }^{5}$ Lúcia COSTA, ${ }^{6}$ Raquel LUCAS $^{1,2}$ and Henrique BARROS ${ }^{1,2}$ \\ ${ }^{1}$ Department of Clinical Epidemiology, Predictive Medicine and Public Health, University of Porto Medical School, ${ }^{2}$ Public Health \\ Institute, University of Porto, Porto, ${ }^{3}$ Nova Medical School/Faculdade de Ciências Médicas, Universidade Nova de Lisboa,CEDOC, \\ ${ }^{4}$ Rheumatology Department, CEDOC, CHLO, EPE - Hospital Egas Moniz, Lisboa, ${ }^{5}$ Hospital Beatriz Ângelo,Loures, Portugal, and \\ ${ }^{6}$ Rheumatology Department, EPE-Hospital S. João, Porto, Portugal
}

\begin{abstract}
Aim: To evaluate the potential role of age, sex, body mass index (BMI), radiographic features and pain in knee osteoarthritis (OA) case ascertainment.

Methods: A cross-sectional study was performed using information from the EPIPorto cohort; social, demographic, behavioral and clinical data was obtained. Pain was assessed using a pain frequency score (regarding ever having knee pain, pain in the last year, in the last 6 months and in the last month). Knee radiographs were classified using the Kellgren-Lawrence scale (0-4). Path analysis was used to assess the plausibility of the causal assumptions and a classification tree to identify characteristics that could improve the identification of patients with radiographic $\mathrm{OA}$.

Results: Higher age and higher BMI were associated with higher radiographic score, but sex had no statistical association. Females, higher age, higher BMI and higher radiographic score were statistically associated with higher pain scores. For both genders, the classification tree estimated age as the first variable to identify individuals with knee radiographic features. In females older than 56 years, pain frequency score is the second discriminator characteristic, followed by age (>65 years) and (BMI $\left.>30 \mathrm{~kg} / \mathrm{m}^{2}\right)$. Higher pain frequency and BMI $>29 \mathrm{~kg} / \mathrm{m}^{2}$ were relevant for identifying OA in men with ages between 43.5 and 55.5 years.

Conclusions: Age, BMI and pain frequency are independently associated with radiographic OA and the use of information on these characteristics can improve the identification of patients with knee OA. Beyond age, pain complaints are particularly relevant but the level of pain is different by sex.
\end{abstract}

Key words: clinical aspects, decision analysis, knee osteoarthritis, pain, radiography.

\section{INTRODUCTION}

Osteoarthritis (OA) is the most common form of joint disease $^{1-3}$ and one of the most important causes of pain and disability worldwide. ${ }^{4}$ Thus, the need to improve case ascertainment and early disease identification is a

Correspondence: Elisabete Ramos, PhD., Department of Clinical Epidemiology, Predictive Medicine and Public Health, University of Porto Medical School, 4200-319 Porto, Portugal.

Email: eliramos@med.up.pt priority in order to allow clinical and public health measures to be taken.

OA can be defined as a multifactorial condition of joint failure mainly characterized by articular cartilage loss and subchondral bone sclerosis. ${ }^{5}$ OA case ascertainment is normally based on pathological changes seen on X-ray and the presence of joint signs and symptoms. ${ }^{6}$ Gradual radiographic evidence of joint damage and an increase in the amount of pain and physical disability are indicators of OA progression. ${ }^{7}$ However, an 
accurate evaluation is difficult because of the non-specific nature of OA signs and symptoms ${ }^{8,9}$ and sometimes their poor association with radiographic findings, ${ }^{10}$ enhancing the need to find clinical and demographic characteristics that can be used in clinical practice to identify persons with this condition.

Among the most common joint sites affected by OA, the knee is one of the most prevalent ${ }^{1}$ and more frequently associated with pain and disability. ${ }^{11,12}$ The understanding of the pathophysiology of joint degeneration that leads to knee OA has been improving and different non-modifiable and modifiable risk factors have been identified. ${ }^{11,13-15}$ Older age, female sex and higher body mass index (BMI) are established risk factors in knee OA, both as determinants and as key factors on disease progression. ${ }^{16-18}$ However, the potential role of a formal inclusion of such factors to improve the ability to identify patients with knee radiographic $\mathrm{OA}$ is not so well understood. ${ }^{19-21}$ Identifying simple clinical and demographic characteristics that can represent a high probability of having radiographic $\mathrm{OA}$ is useful, particularly in situations where radiography might be difficult, undesirable, or even to decide if it is necessary. On the other hand, as OA-related pain is the reason that most often leads to the demand for health care, it is important to understand how these characteristics are related, and can contribute to an early identification of patients.

The purpose of this study is to evaluate the role of pain, together with age, sex and BMI, in the identification of patients with knee radiographic OA.

\section{MATERIALS AND METHODS}

\section{Data collection}

The study was performed using information collected as part of the EPIPorto cohort. ${ }^{22}$ Briefly, this cohort evaluates non-institutionalized adults, resident in Porto, an urban centre located in northwest Portugal with almost 400000 inhabitants. Participants were selected by random digit dialling and invited to visit the University of Porto Medical School for an evaluation, which included an interview based on a structured questionnaire on social, demographic, behavioral and clinical data. The proportion of participation was $70 \%$. The local ethics committee of S. João Hospital, a university hospital, approved the study protocol. All participants gave written consent to participate in the study, which was carried out in accordance with the Helsinki Declaration.

Data were collected by trained interviewers using structured questionnaires. We evaluated marital status (categorized into either married/civil union and single/ divorced/widow), years of education (measured as the number of successfully completed years of formal schooling), occupation (white collar, blue collar and others, including students, unemployed and those who never had a job) and current occupational status (working, retired and others). A previous medical diagnosis of chronic diseases in general and of knee OA was evaluated by self-reported information.

Frequency of knee pain was evaluated using a set of 'yes/no' questions. First, participants were asked if they 'ever had knee pain not related with any trauma or injury?' If participants gave a positive answer to this question they were asked to answer (yes/no) to three further questions: 'In the last year did you have more than 3 knee pain episodes?'; 'During the last 6 months did knee pain last longer than a week?'; and 'During the last month did you have knee pain?' To understand if these questions could be used to measure the frequency of knee pain, factor analysis for dichotomous variables was performed. Pain intensity was also measured using the Visual Analogue Pain Scale (VAS) $(0-100 \mathrm{~mm})^{23}$ in the different time frames evaluated by the questions (at the moment, in the last year, in the last 6 months and in the last month).

Body weight was measured to the nearest $0.1 \mathrm{~kg}$ using a digital scale $\left(\mathrm{SECA}^{\circledast}\right)$ and height was measured to the nearest centimeter using a wall-stadiometer $\left(\mathrm{SECA}^{\circledR}\right)$; then using BMI (weight $[\mathrm{kg}] /$ height $\left[\mathrm{m}^{2}\right]$ ) we classified participants into three categories $(<25.0 \mathrm{~kg} /$ $\mathrm{m}^{2}$ underweight or normal; $25.0-29.9 \mathrm{~kg} / \mathrm{m}^{2}$ overweight; $\geq 30 \mathrm{~kg} / \mathrm{m}^{2}$ obese). ${ }^{24}$

Weight-bearing antero-posterior ${ }^{19}$ and lateral, semiflexed $\left(45^{\circ} \text { flexion }\right)^{25}$ radiographs of knees were obtained. Radiographic knee OA was evaluated in tibiofemoral (medial and lateral) and patello-femoral compartments of the right and left knee, and graded according to the Kellgren-Lawrence scale (KL: ${ }^{5}$ Grade 0, none, no visible features of OA; Grade 1, doubtful, questionable osteophytes or questionable joint space narrowing; Grade 2, minimal, definitive small osteophytes, little/mild joint space narrowing; Grade 3, moderate, definitive moderate osteophytes, joint space narrowing of at least 50\%; Grade 4, severe, joint space impaired severely, cysts and sclerosis of subchondral bone. ${ }^{26,27}$ Radiographs were scored only by one reader, although he was unaware of the participants' clinical data.

\section{Participants}

From the 2485 participants of the EPIPorto cohort that participated at the baseline evaluation, 1682 were 
re-evaluated during the follow-up performed between 2005 and 2008. From those, the first 1000 were systematically invited to have knee radiographs and 907 were evaluated; from these 13 participants had unreadable or incomplete knee radiographic evaluation. The final sample comprised the 894 participants with complete data on knee OA.

\section{Data analysis}

Quantitative variables were described by mean (standard deviation) and qualitative variables were described by absolute and relative frequency.

The mean comparisons were made using independent samples $t$-test or Mann-Whitney $U$ test for skewed distributions and the proportion comparisons were made using the Chi-square test.

Principal components analysis and factor analysis for dichotomous variables (latent trait model) were used to evaluate the dimensionality of radiographic knee OA (in order to identify the best way to summarize radiographic lesions) and in the pain questions (to measure the frequency of knee pain), respectively. The internal consistency of both was assessed by Cronbach's alpha.

Pain questions were considered as a score for knee pain, with an increase in score representing an increase in pain frequency. Score -1 represents participants with no knee pain; score 0 represents those that reported 'ever had knee pain' but reported no pain in the last year; participants were scored from 1 to 3 , according to the number of positive answers regarding 'the last year', 'the last 6 months' and 'the last month'. Path analysis was used to evaluate the role of gender, BMI and age in pain frequency and radiographic scores. Path analysis is an extension of regression analysis which allows for simultaneous estimation of the interrelations between variables in a set. ${ }^{28}$ This technique is being increasingly used to deconstruct and compare the magnitudes of effects between variables with complex interrelations or to test the plausibility of mediation effects. ${ }^{29}$ Path analysis was fitted with Mplus software (Muthén and Muthén, Los Angeles, CA, USA). The association between age, sex, BMI, pain frequency and radiographic scores were estimated by correlation coefficients and respective 95\% confidence intervals. Goodness of fit was evaluated using $\chi^{2}$ for model fit, comparative fit index, Tucker-Lewis Index, root mean square error of approximation and square root mean residual according to the Akaike and Bayesian criteria. ${ }^{28}$ Radiographic scores used in the path analyses were computed by the numeric mean of the scores of each of the six joint compartments evaluated.
A decision tree to estimate radiographic knee OA was constructed separately by sex using all variables that had shown to have a direct or indirect effect on path analyses. The radiographic score equal to 2 or more in at least one of the six joint compartments evaluated (having radiographic knee OA) was our major outcome. The Rpart and Ltm pakages from $R{ }^{\circledR}$, a language and environment for statistical computing, were used to estimate the decision tree and the latent trait model. ${ }^{28}$

\section{RESULTS}

Our sample was composed mainly of females (59.2\%); the overall mean (standard deviation) age was 58.1 (14.2) years. Knee pain 'ever having knee pain not related with any trauma or injury' was reported by $43.8 \%$ of participants and knee radiographic OA $(K L \geq 2)$ was present in $46.2 \%$. There was a significantly lower proportion of females, a significantly higher proportion of overweight/obese individuals and lower education levels among the included participants compared to those who were not included in this analysis (Table 1).

A principal component analysis considering all the joint compartments evaluated was performed in order to test if the mean score of all knee radiographs evaluated was a good summary measure to describe radiographic OA features. This analysis allowed us to identify only one component for knee radiographic OA features, that explained $67.0 \%$ of the variance and a Cronbach's alpha of 0.90 (Table 2). So, we estimated a mean score based on all joint compartments of left and right knees.

Factor analysis was used to understand how to summarize the data obtained in the knee pain frequency questions (dichotomous variables): it identified only one factor and all items showed a factor loading higher than 0.86, with a global Cronbach's alpha of 0.70 (Table 2).

Figure 1 presents the causal pathways assumed for testing the relations between age, sex, BMI, radiographic score and pain frequency score that allowed us to obtain a summary model of these relations: $\chi^{2}$ for model fit was $0.02 \quad(P=0.88)$; comparative fit index $=1.00$, Tucker-Lewis Index $=1.02$, root mean square error of approximation $<0.01$ and square root mean residual $<0.01$. Association between variables was described by correlation coefficients (95\% confidence intervals). Age and BMI were used as continuous variables in the path analysis which then provided the cut-off values described in Fig. 1. We observed no effect of sex on radiographic lesions, but age and BMI were 
Table 1 Comparison between included and excluded participants

\begin{tabular}{|c|c|c|c|}
\hline & $\begin{array}{c}\text { Excluded } \\
n=788\end{array}$ & $\begin{array}{c}\text { Evaluated } \\
n=894\end{array}$ & $P$-value \\
\hline $\begin{array}{l}\text { Age (years), } \\
\text { mean (SD) }\end{array}$ & $56.7(15.4)$ & $58.1(14.2)$ & 0.05 \\
\hline \multicolumn{4}{|l|}{ Sex, $n(\%)$} \\
\hline Women & $518(65.7)$ & $529(59.2)$ & $<0.01$ \\
\hline \multicolumn{4}{|l|}{ Marital status, $n(\%)$} \\
\hline Married & $523(66.4)$ & $611(68.3)$ & \multirow[t]{2}{*}{0.75} \\
\hline $\begin{array}{l}\text { Single or } \\
\text { divorced }\end{array}$ & $265(33.6)$ & $283(31.7)$ & \\
\hline \multicolumn{4}{|c|}{ Years of education, $n(\%)$} \\
\hline $0-4$ years & $279(35.4)$ & $330(37.0)$ & \multirow[t]{4}{*}{$<0.01$} \\
\hline 5-9 years & $140(17.8)$ & $224(25.1)$ & \\
\hline $10-12$ years & $127(16.1)$ & $123(13.8)$ & \\
\hline$\geq 12$ years & $242(30.7)$ & $216(24.2)$ & \\
\hline \multicolumn{4}{|l|}{ Occupation, $n(\%)$} \\
\hline $\begin{array}{l}\text { White collar } \\
\text { occupations }\end{array}$ & $468(59.4)$ & $530(59.4)$ & \multirow[t]{3}{*}{0.39} \\
\hline $\begin{array}{l}\text { Blue collar } \\
\text { occupations }\end{array}$ & $248(31.5)$ & $264(29.6)$ & \\
\hline $\begin{array}{l}\text { Others } \\
\text { (unemployed, } \\
\text { student, never } \\
\text { had a job) }\end{array}$ & $72(9.1)$ & $98(11.0)$ & \\
\hline \multicolumn{4}{|c|}{ Current occupation status, $n(\%)$} \\
\hline Working & $344(43.7)$ & $357(40.0)$ & \multirow[t]{3}{*}{0.14} \\
\hline Retired & $333(42.3)$ & $383(42.9)$ & \\
\hline $\begin{array}{l}\text { Others } \\
\text { (unemployed, } \\
\text { student, never } \\
\text { had a job) }\end{array}$ & $111(14.1)$ & $153(17.1)$ & \\
\hline \multicolumn{4}{|c|}{ Self-reported diagnosis of knee OA, $n(\%)$} \\
\hline Yes & $109(13.9)$ & $144(16.1)$ & 0.11 \\
\hline \multicolumn{4}{|c|}{ Other chronic disease, $n(\%)$} \\
\hline Yes & $539(69.5)$ & $590(66.4)$ & 0.10 \\
\hline $\begin{array}{l}\text { Height }(\mathrm{cm}) \text {, } \\
\text { mean }(\mathrm{SD})\end{array}$ & $160.00(9.08)$ & $160.47(9.22)$ & 0.29 \\
\hline $\begin{array}{l}\text { Weight }(\mathrm{kg}) \\
\text { mean }(\mathrm{SD})\end{array}$ & $70.01(28.71)$ & $70.42(13.33)$ & 0.70 \\
\hline \multicolumn{4}{|c|}{ Body mass index $\left(\mathrm{kg} / \mathrm{m}^{2}\right), n(\%)$} \\
\hline$<25.0 \mathrm{~kg} / \mathrm{m}^{2}$ & $293(37.8)$ & $273(31.0)$ & 0.01 \\
\hline $25.0-29.9 \mathrm{~kg} / \mathrm{m}^{2}$ & $297(38.3)$ & $382(43.4)$ & \\
\hline$\geq 30.0 \mathrm{~kg} / \mathrm{m}^{2}$ & $186(24.0)$ & $226(24.9)$ & \\
\hline \multicolumn{4}{|l|}{ Knee pain 'ever' } \\
\hline Yes & $315(40.2)$ & $391(43.8)$ & 0.14 \\
\hline
\end{tabular}

$\mathrm{OA}$, osteoarthritis; $\mathrm{SD}$, standard deviation.

positively associated with higher radiographic score. Regarding pain frequency score, we found a direct and positive effect from radiographic score, showing that pain is in part explained by OA radiographic features. However, pain frequency score is also explained by sex
Table 2 Principal component analysis for knee radiographic features and internal consistency/factor analysis for dichotomous variables (latent trait model) for knee pain questions

\begin{tabular}{|c|c|c|c|}
\hline $\begin{array}{l}\text { Radiographic } \\
\text { features }\end{array}$ & Component 1 & $\begin{array}{c}\text { \% of } \\
\text { variance } \\
\text { explained }\end{array}$ & $\begin{array}{c}\text { Global } \\
\text { Cronbach's } \\
\text { alpha }\end{array}$ \\
\hline $\begin{array}{l}\text { Right knee medial } \\
\text { tibio-femoral OA }\end{array}$ & 0.84 & \multirow[t]{6}{*}{$67.0 \%$} & \multirow[t]{6}{*}{0.90} \\
\hline $\begin{array}{l}\text { Left knee medial } \\
\text { tibio-femoral OA }\end{array}$ & 0.82 & & \\
\hline $\begin{array}{l}\text { Right knee lateral } \\
\text { tibio-femoral OA }\end{array}$ & 0.80 & & \\
\hline $\begin{array}{l}\text { Left knee lateral } \\
\text { tibio-femoral OA }\end{array}$ & 0.83 & & \\
\hline $\begin{array}{l}\text { Right knee } \\
\text { patello-femoral OA }\end{array}$ & 0.82 & & \\
\hline $\begin{array}{l}\text { Left knee } \\
\text { patello-femoral OA }\end{array}$ & 0.81 & & \\
\hline Pain questions & $\begin{array}{l}\text { Factor } \\
\text { loading }\end{array}$ & $\begin{array}{l}\text { Cronbach's } \\
\text { alpha } \\
\text { f item deleted }\end{array}$ & $\begin{array}{c}\text { Global } \\
\text { Cronbach's } \\
\text { alpha }\end{array}$ \\
\hline $\begin{array}{l}\text { 'In the last year } \\
\text { did you had more } \\
\text { than three knee } \\
\text { pain episodes?' }\end{array}$ & 0.97 & 0.51 & 0.70 \\
\hline $\begin{array}{l}\text { 'During the last } \\
6 \text { months did knee } \\
\text { pain last longer } \\
\text { than a week?' }\end{array}$ & 0.86 & 0.74 & \\
\hline $\begin{array}{l}\text { 'During the } \\
\text { last month did you } \\
\text { have knee pain?' }\end{array}$ & 0.95 & 0.52 & \\
\hline
\end{tabular}

OA, osteoarthritis.

(lower pain scores were reported by males), by BMI (higher BMI is associated with higher pain score) and, although with a small association, by age (higher age contributed to higher pain score).

For both genders the classification tree identified age, BMI and pain frequency as relevant variables to identify participants with radiographic OA (radiographic score equal to 2 or more, in at least one joint compartment). For females (Fig. 2), among those aged $\geq 56.5$ years the presence of pain is a major predictor of radiographic OA (more than $80 \%$ ). In the absence of pain, having more than 65.5 years or a $\mathrm{BMI} \geq 30.5 \mathrm{~kg} / \mathrm{m}^{2}$ can predict an increased likelihood of having OA. This classification tree model presented an acceptable goodness of fit based on receiver operating characteristic (ROC) of 0.73 , sensitivity $(80 \%)$, specificity $(67 \%)$, positive predictive value $(77 \%)$ and negative predictive value $(71 \%)$. 


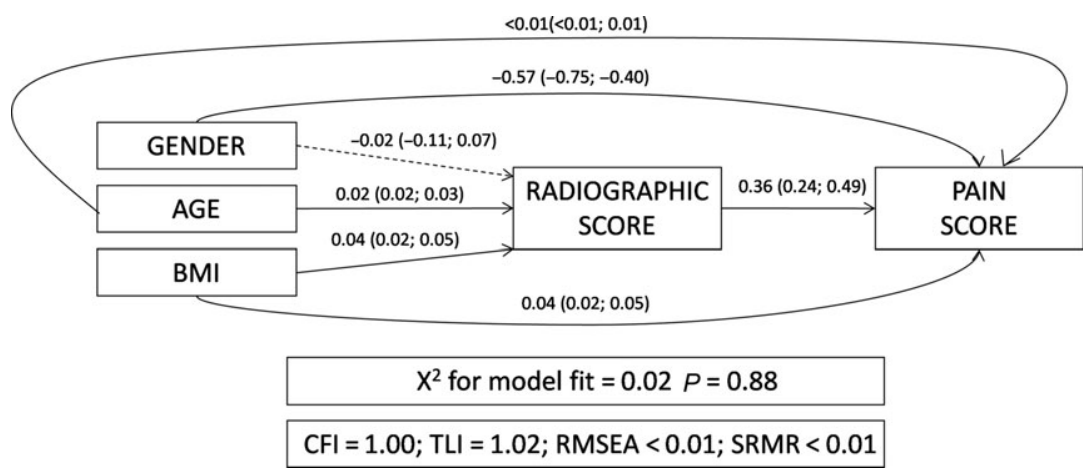

Figure 1 Path analysis between sex, age, BMI (body mass index), radiographic score and pain frequency score.

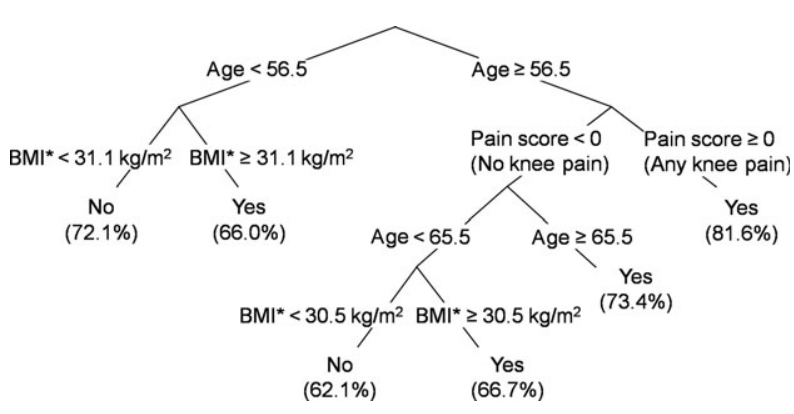

Figure 2 Classification tree for the prediction of radiographic osteoarthritis (OA) in females. BMI, body mass index.

For males (Fig. 3), the first predictor was age $\geq 55.5$ years. Among males aged $\geq 43.5$ and $<55.5$ years, having pain complaints in the last year, month or week (pain frequency score $\geq 1.5$ ) or a BMI $\geq 29.3 \mathrm{~kg} / \mathrm{m}^{2}$ represents an increased likelihood of having OA. The ROC was 0.70 , with a higher sensitivity $(88 \%)$ but a lower specificity (52\%) compared with the model for females. Positive predictive value and negative predictive value were, respectively, $72 \%$ and $76 \%$.

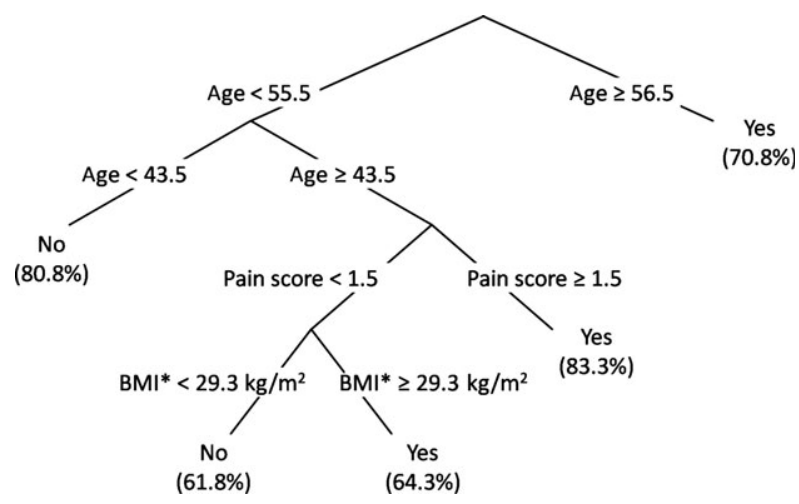

Figure 3 Classification tree for the prediction of radiographic osteoarthritis (OA) in males. BMI, body mass index.

\section{DISCUSSION}

Although OA risk factors have been extensively studied worldwide, it is important to understand the role of age, sex, BMI and pain in the probability of having radiographic OA. Simple variables can allow predicting the need to perform a radiographic exam or, when it is not possible, they can help to understand which radiographic findings can be expected.

In both clinical practice and in the research setting the measurement of OA-related pain is a challenge. ${ }^{30,31}$ Our previous work ${ }^{32}$ showed that two of the questions presented a high sensitivity but a low specificity but when we considered all of them, there was a slight increase in the ability to identify participants with radiographic $\mathrm{KL} \geq 2$.

This reduced ability to identify participants with OA based on pain complaints, is in accordance with a meta-analysis which found that a higher number of questions related to pain allowed improved sensitivity but implied a large restriction of specificity. ${ }^{33}$

Our pain frequency score was based in a small number of questions, with any hierarchy on complaints, created by a group of health professionals with field clinical expertise and that could be easily used in a clinical setting or in population-based studies. It showed an acceptable performance (in terms of the internal consistency of the three items associated with pain frequency score) allowing us to assume it as a good measure. The use of this score allowed us to have an easy summary measure of pain and to order pain complaints instead of a dichotomous approach (pain present or absent) that was unable to take in account the complexity of pain complaints. As previously reported ${ }^{32}$ higher discriminatory ability to identify participants with radiographic OA was found using the pain frequency score compared with single questions on knee pain.

Pain intensity may also be an important aspect in OA case ascertainment. ${ }^{19}$ We tried to use pain intensity 
assessment, obtained through the visual analogue pain scale, but this information did not improve our model for the prediction of knee radiographic OA (even when we used data specific for each of the time periods evaluated). Furthermore, our decision tree statistical criteria did not include these variables as relevant to explaining radiographic OA features and identified the pain score without the pain quantification as the most relevant variable; the best model fit was obtained only with pain frequency data and therefore data for pain intensity was not considered in our model.

Some of the radiographic and pain discordance in knee OA may be in part related to the fluctuating nature of knee pain. ${ }^{34}$ Pain questions did not evaluate the mechanical component of pain that is an important aspect in OA. Also, the recall bias in pain assessment can be a limitation, especially since episodes that occurred over time, or are less serious, were less likely to be remembered.

The differences in the associations between radiographic and outcome measures might also be related to the radiographic views and classification used. ${ }^{35}$ It is known that multiple views detect more radiographic OA changes than single views alone $e^{36}$ and weight-bearing antero-posterior and lateral radiographs may not be sufficient to show the true extent of the pathology. ${ }^{37}$ Moreover, the radiographic evaluation according to the KL score of 2-4 has some known limitations. ${ }^{26,36,38}$ Nevertheless, the radiographic views selected are frequently used $^{35}$ and no important bias is expected in our OA classification of radiographs, since they were scored only by one reader that was blinded to all clinical data of the participant.

We used a mean radiographic score (evaluating all joint compartments of the left and right knees) and we considered a participant with a score $\geq 2$ has having radiographic OA. Although we performed a principal component analysis this measure of radiographic features has not been validated and this can be a study limitation.

Path analysis was used as an approach to understand the mechanisms beyond individual risk factors, radiographic features and complaints of pain. ${ }^{29}$ Our model showed good fitting parameters and identified that higher age and higher BMI were associated with higher radiographic score. This is in accordance with previous studies that identified these aspects as important determinants of knee OA occurrence and progression. ${ }^{11,13}$

Age is a strong predictor of OA development. ${ }^{39}$ The vulnerabilities of a joint that occur as part of the aging process make it susceptible to disease; ${ }^{40}$ diminished capacity for cartilage repair, hormonal changes and the cumulative effects of environmental exposures are possible age-related mechanisms. ${ }^{41}$

Higher BMI is known as one of the most important risk factors for knee $\mathrm{OA}^{12,17,42}$ and is a predictor of OA progression. $^{3}$ Overweight and obesity associated with $\mathrm{OA}$ is probably the result of a mechanical process with an increased of load and stress for the joints; ${ }^{11,42,43}$ another possible explanation is associated with the pro-inflammatory action of fat. ${ }^{44,45}$ Furthermore, the majority of people with OA have at least one co-morbid condition $^{46}$ and higher age and higher BMI increases the prevalence of multiple co-morbid conditions which in turn increases the impact of OA. ${ }^{1}$

Even though some theoretical pathophysiological mechanisms can be proposed to explain sex differences on the incidence of $\mathrm{OA}^{7,11}$ and several studies have found that females may have higher risks of development and progression than males, ${ }^{13,47,48}$ our path analysis did not find a statistical association between gender and radiographic scores. However, it is possible that the higher incidence of $\mathrm{OA}$ found in females by population studies can be explained more by a higher probability of complaints reported by females, and therefore an increase the likelihood of diagnosis, rather than by a real gender differences in the occurrence of OA. ${ }^{6,19}$

As far as pain frequency score is concerned, we found that more severe radiographic features presented a strong association with higher pain scores. This supports the relevance of pain as an important marker of $\mathrm{OA}$ and is in accordance with data showing that pain is frequently the primary reason for seeking health care. ${ }^{1,42}$ Nevertheless, pain is highly associated with physical and psycho-social aspects besides pathological changes and this can explain the high variability of results found in the literature, ${ }^{49}$ notwithstanding our results reinforcing the need to measure and understand pain complaints, especially in younger people.

Although radiographic features are a useful objective marker of $\mathrm{OA}$, this information alone has limited clinical value $^{36}$ and needs to be understood in the context of other clinical signs. On the other hand, it is important to understand that several variables can predict a positive radiographic evaluation in OA. These characteristics may represent a high probability of radiographic $\mathrm{OA}$ and can be used in clinical practice to identify persons with the condition, particularly in situations where radiography is not available. Based on the classification tree, age was the first variable that identified individuals with radiographic features ( $\geq 56.5$ years) in both gen- 
ders. In females older than 56 years, pain frequency score is the second discriminator characteristic, followed by age $(>65)$ and (BMI $\left(>30 \mathrm{~kg} / \mathrm{m}^{2}\right)$. Pain frequency score $\geq 1.5$ and $\mathrm{BMI}>29 \mathrm{~kg} / \mathrm{m}^{2}$ were relevant for identifying OA in men with ages between 43.5 and 55.5 years. This was in accordance with the previous associations found in our path analysis and in accordance with established guidelines ${ }^{33,50}$ that include the need to consider radiographic findings in accordance with age, BMI and pain for a correct OA case ascertainment and management. Overall, the analysis that we present, allowed us to identify cut-offs for each of these widely known characteristics that can be used according to the set of patient characteristics.

Our results need to be understood remembering that several other factors play an important role in OA development. Biomechanical factors can also contribute to OA, such as, for example, malaligned joints, proprioceptive deficits and muscle weakness; ${ }^{19}$ other systemic factors such as pre- and post-menopausal status in women $^{51}$ could also influence OA. These aspects, not evaluated in this study, should be part of a more comprehensive study in the future.

The major limitation of this study is its cross-sectional design, which does not allow the exploration of how observed differences have been developed and interact over time; however, since we are estimating the probability of having radiographic OA changes, this aspect does not have a relevant effect.

Although our study was developed from a population-based study, and the differences between excluded and included are slight, losses of follow-up may cause selection bias which could limit the generalizability of these results. Moreover, the interpretation of the results of our model should be made taking into concern the low specificity found in males.

In clinical practice, understanding simple clinical variables can improve OA case ascertainment and early disease identification. Although our study has limitations, our results can aid the clinician to understand how to deal with age, sex, BMI and pain in the identification of knee OA patients. Due to the fact that the present study has only analyzed data from knee joints, the implication of these results on patients with $\mathrm{OA}$ in other joint sites is limited.

In conclusion, we identified that in knee OA, older age and higher BMI were associated with higher radiographic score, but sex had no statistical association. Females, higher age, higher BMI and higher radiographic score were statistically associated with higher pain scores. Although pain complaints are also depen- dent on sex and BMI, its measurement is useful to identify patients with radiographic OA, particularly in younger non-obese individuals.

\section{DISCLOSURES}

No further contributions or research funding sources need to be reported. The authors declare that they have no conflict of interests.

\section{REFERENCES}

1 Arden N, Nevitt MC (2006) Osteoarthritis: epidemiology. Best Pract Res Clin Rheumatol 20, 3-25.

2 Hochberg MC (2012) Osteoarthritis year 2012 in review: clinical. Osteoarthritis Cartilage 20 (12), 1465-9.

3 Petersson IF, Jacobsson LT (2002) Osteoarthritis of the peripheral joints. Best Pract Res Clin Rheumatol 16 (5), 741-60.

4 Woolf A, Pfleger B (2003) Burden of major musculoskeletal conditions. Bull World Health Organ 81, 646-56.

5 Lawrence RC, Helmick CG, Arnett FC et al. (1998) Estimates of the prevalence of arthritis and selected musculoskeletal disorders in the United States. Arthritis Rheum 41 (5), 778-99.

6 Kopec JA, Rahman MM, Berthelot JM et al. (2007) Descriptive epidemiology of osteoarthritis in British Columbia, Canada. J Rheumatol 34 (2), 386-93.

7 Lanyon P, Muir K, Doherty S et al. (2003) Age and sex differences in hip joint space among asymptomatic subjects without structural change: implications for epidemiologic studies. Arthritis Rheum 48 (4), 1041-6.

8 Zhang W, Doherty M, Arden N et al. (2005) EULAR evidence based recommendations for the management of hip osteoarthritis: report of a task force of the EULAR Standing Committee for International Clinical Studies Including Therapeutics (ESCISIT). Ann Rheum Dis 64 (5), 669-81.

9 Zhang W, Doherty M, Leeb BF et al. (2007) EULAR evidence based recommendations for the management of hand osteoarthritis: report of a Task Force of the EULAR Standing Committee for International Clinical Studies Including Therapeutics (ESCISIT). Ann Rheum Dis 66 (3), 377-88.

10 Buckwalter JA, Saltzman C, Brown T (2004) The impact of osteoarthritis: implications for research. Clin Orthop Relat Res 427(Suppl.), S6-15.

11 Cooper C, Snow S, McAlindon TE et al. (2000) Risk factors for the incidence and progression of radiographic knee osteoarthritis. Arthritis Rheum 43 (5), 995-1000.

12 Lau EC, Cooper C, Lam D et al. (2000) Factors associated with osteoarthritis of the hip and knee in Hong Kong Chinese: obesity, joint injury, and occupational activities. Am J Epidemiol 152 (9), 855-62. 
13 Felson DT, Zhang Y, Hannan MT et al. (1997) Risk factors for incident radiographic knee osteoarthritis in the elderly: the Framingham Study. Arthritis Rheum 40 (4), 728-33.

14 Wu CW, Morrell MR, Heinze E et al. (2005) Validation of American College of Rheumatology classification criteria for knee osteoarthritis using arthroscopically defined cartilage damage scores. Semin Arthritis Rheum 35, 197-201.

15 Yoshida S, Aoyagi K, Felson DT et al. (2002) Comparison of the prevalence of radiographic osteoarthritis of the knee and hand between Japan and the United States. J Rheumatol 29 (7), 1454-8.

16 Du H, Chen SL, Bao CD et al. (2005) Prevalence and risk factors of knee osteoarthritis in Huang-Pu District, Shanghai. China. Rheumatol Int 25, 585-90.

17 Grotle M, Hagen KB, Natvig B et al. (2008) Obesity and osteoarthritis in knee, hip and/or hand: an epidemiological study in the general population with 10 years followup. BMC Musculoskelet Disord 9, 132.

18 Lacey RJ, Thomas E, Duncan RC et al. (2008) Gender difference in symptomatic radiographic knee osteoarthritis in the Knee Clinical Assessment-CAS(K): a prospective study in the general population. BMC Musculoskelet Disord 9, 82 .

19 Felson DT (2009) Developments in the clinical understanding of osteoarthritis. Arthritis Res Ther 11 (1), 203.

20 Peat G, Thomas E, Duncan R et al. (2006) Clinical classification criteria for knee osteoarthritis: performance in the general population and primary care. Ann Rheum Dis 65 (10), 1363-7.

21 Zhang W, Nuki G, Moskowitz RW et al. (2010) OARSI recommendations for the management of hip and knee osteoarthritis: part III: Changes in evidence following systematic cumulative update of research published through January 2009. Osteoarthritis Cartilage 18 (4), 476-99.

22 Ramos E, Lopes C, Barros H (2004) Investigating the effect of nonparticipation using a population-based case-control study on myocardial infarction. Ann Epidemiol 14, 437-41.

23 Huskisson EC (1982) Measurement of pain. J Rheumatol 19 (5), 768-9.

24 Oliveira A, Ramos E, Lopes C et al. (2009) Self-reporting weight and height: misclassification effect on the risk estimates for acute myocardial infarction. Eur J Public Health 19 (5), 548-53.

25 LaValley MP, McLaughlin S, Goggins J et al. (2005) The lateral view radiograph for assessment of the tibiofemoral joint space in knee osteoarthritis: its reliability, sensitivity to change, and longitudinal validity. Arthritis Rheum 52 (11), 3542-7.

26 Altman R, Asch E, Bloch D et al. (1986) Development of criteria for the classification and reporting of osteoarthritis. Classification of osteoarthritis of the knee. Diagnostic and Therapeutic Criteria Committee of the American Rheumatism Association. Arthritis Rheum 29 (8), 1039-49.

27 Dahaghin S, Bierma-Zeinstra SM, Ginai AZ et al. (2005 May) Prevalence and pattern of radiographic hand osteo- arthritis and association with pain and disability (the Rotterdam study). Ann Rheum Dis 64 (5), 682-7.

28 Lucas R, Ramos E, Severo M et al. (2011) Potential for a direct weight-independent association between adiposity and forearm bone mineral density during adolescence. Am J Epidemiol 174 (6), 691-700.

29 Loehlin J (2003). Latent Variable Models: An Introduction to Factor, Path, and Structural Equation Analysis. Psychology Press, UK.

30 Hannan MT, Felson DT, Pincus T (2000) Analysis of the discordance between radiographic changes and knee pain in osteoarthritis of the knee. J Rheumatol 27 (6), 1513-7.

31 O'Reilly SC, Muir KR, Doherty M (1996) Screening for pain in knee osteoarthritis: which question? Ann Rheum Dis 55, 931-3.

32 Pereira D, Severo M, Barros H et al. (2013) The effect of depressive symptoms on the association between radiographic osteoarthritis and knee pain: a cross-sectional study. BMC Musculoskelet Disord 14 (1), 214.

33 Zhang W, Doherty M, Peat G et al. (2010) EULAR evidence-based recommendations for the diagnosis of knee osteoarthritis. Ann Rheum Dis 69 (3), 483-9.

34 Neogi T, Nevitt MC, Yang M et al. (2010) Consistency of knee pain: correlates and association with function. Osteoarthritis Cartilage 18 (10), 1250-5.

35 Kinds MB, Welsing PM, Vignon EP et al. (2011) A systematic review of the association between radiographic and clinical osteoarthritis of hip and knee. Osteoarthritis Cartilage 19 (7), 768-78.

36 Duncan RC, Hay EM, Saklatvala J et al. (2006) Prevalence of radiographic osteoarthritis-it all depends on your point of view. Rheumatology (Oxford) 45 (6), 757-60.

37 Buckland-Wright C (2006) Which radiographic techniques should we use for research and clinical practice? Best Pract Res Clin Rheumatol 20, 39-55.

38 Altman RD, Block DA, Brandt KD et al. (1990) Osteoarthritis: definitions and criteria. Ann Rheum Dis 49, 201.

39 Felson DT, Zhang Y, Hannan MT et al. (1995) The incidence and natural history of knee osteoarthritis in the elderly. The Framingham Osteoarthritis Study. Arthritis Rheum 38 (10), 1500-5.

40 Felson DT, Nevitt MC (2004) Epidemiologic studies for osteoarthritis: new versus conventional study design approaches. Rheum Dis Clin North Am 30(4), 783-97, vii.

41 Hart DJ, Doyle DV, Spector TD (1999) Incidence and risk factors for radiographic knee osteoarthritis in middle-aged women: the Chingford Study. Arthritis Rheum 42, 17-24.

42 Felson DT, Zhang Y (1998) An update on the epidemiology of knee and hip osteoarthritis with a view to prevention. Arthritis Rheum 41 (8), 1343-55.

43 Cooper C, McAlindon T, Snow S et al. (1994) Mechanical and constitutional risk factors for symptomatic knee osteoarthritis: differences between medial tibiofemoral and patellofemoral disease. J Rheumatol 21 (2), 307-13. 
44 Madry H, Luyten FP, Facchini A (2012) Biological aspects of early osteoarthritis. Knee Surg Sports Traumatol Arthrosc 20 (3), 407-22.

45 van der Kraan PM (2012) Osteoarthritis year 2012 in review: biology. Osteoarthritis Cartilage 20 (12), 144750.

46 Spector TD, MacGregor AJ (2004) Risk factors for osteoarthritis: genetics. Osteoarthritis Cartilage 12(Suppl. A), S3944.

47 Andrianakos AA, Kontelis LK, Karamitsos DG et al. (2006) Prevalence of symptomatic knee, hand, and hip osteoarthritis in Greece. The ESORDIG study. J Rheumatol 33 (12), 2507-13.

48 Oliveria SA, Felson DT, Reed JI et al. (1995) Incidence of symptomatic hand, hip, and knee osteoarthritis among patients in a health maintenance organization. Arthritis Rheum 38 (8), 1134-41.

49 Paradowski PT, Englund M, Lohmander LS et al. (2005) The effect of patient characteristics on variability in pain and function over two years in early knee osteoarthritis. Health Qual Life Outcomes 3, 59.

50 Hochberg MC, Altman RD, April KT et al. (2012) American College of Rheumatology 2012 recommendations for the use of nonpharmacologic and pharmacologic therapies in osteoarthritis of the hand, hip, and knee. Arthritis Care Res (Hoboken) 64 (4), 455-74.

51 Hanna FS, Wluka AE, Bell RJ et al. (2004) Osteoarthritis and the postmenopausal woman: epidemiological, magnetic resonance imaging, and radiological findings. Semin Arthritis Rheum 34 (3), 631-6. 